\title{
BUSCANDO PRESERVAR A INTEGRIDADE DA UNIDADE FAMILIAR: A FAMÍLIA VIVENDO A EXPERIÊNCIA DE TER UM FILHO NA UTI
}

\section{TRYING TO PRESERVE THE INTEGRITY OF THE FAMILY UNIT: THE FAMILY LIVING WITH THE EXPERIENCE OF HAVING A CHILD IN THE PEDIATRIC INTENSIVE CARE UNIT}

\author{
Regina Szylit Rousso` \\ Margareth Angelo**
}

BOUSSO, RS; ANGELO,M. Buscando preservar a integridade da unidade familiar: a família vívendo a experiência de ter um filho na UTI. Rev Esc Enf USP, v. 35, n. 2, p. 172-9, jun. 2001.

\begin{abstract}
RESUMO
Este estudo teve como objetivos: compreender o funcionamento da dinâmica familiar da criança internada em UTI pediátrica e construir um Modelo Teórico sobre a experiência da família que vivencia a internação da criança na UTI pediátrica. Utilizou-se como referencial teórico o Interacionismo Simbólico e como referencial metodológico a Teoria Fundamentada nos Dados. A análise comparativa dos dados possibilitou identificar dois fenômenos que compõem esta experiência da família: Tendo uma ruptura familiar e Vivendo a possibilidade de vir a perder o filho. $A$ articulação desses fenômenos permitiu identificar a categoria central BUSCANDO PRESERVAR A INTEGRIDADE DA UNIDADE FAMILIAR, a partir da qual propõe-se um modelo teórico explicativo da experiência.
\end{abstract}

PALAVRAS-CHAVE: Enfermagem de família. Família. Unidades de Terapia Intensiva. Criança hospitalizada. ABSTRACT

\begin{abstract}
The purposes of this study were to: understand the dynamic functioning of the family with a child admitted to a pediatric intensive care unit (PICU) and to construct a theoretical model about the living experience of a family with a child admitted to the PICU. The study used as a theoretical reference the Symbolic Interactionism, and the Grounded theory methodology. The comparative analysis of the data permitted identify two phenomena: Having a family rupture and Living with the possibility of loosing a child. The relationship of these phenomena has permitted the identification of the core category TRYING TO PRESERVE THE INTEGRITY OF THE FAMILY UNIT based on which it was possible to propose a theoretical model to explain the experience.
\end{abstract}

KEYWORDS: Family nursing. Family. Intensive Care Units. Child hospitalized.

A enfermagem sempre reconheceu a importância da família na promoção e manutenção da saúde. Segundo WHALL; FAWCETT (1991), descreve que Florence Nightingale demonstrava preocupação com os familiares dos soldados doentes, no sentido de proporcionar melhores acomodações para estas pessoas.

Nas últimas duas décadas, tem havido um movimento de se recriar e redescobrir como a família possa ser envolvida na prática da enfermagem. Isto é evidenciado pelo uso de termos como Enfermagem da família indicado nos trabalhos como os de FRIEDMAN (1986), GILLS et al. (1989), WRIGTH; LEAHEY(1994) e WRIGTH; WATSON; BELL (1996).
Um novo caminho dentro da enfermagem é trazido por WRIGTH; LEAHEY (1990) : A Enfermagem de Família, na qual a familia é o foco do cuidado. Assim, novas abordagens teóricas têm sido discutidas no sentido de proporcionar melhor compreensão e suporte à enfermagem da família. Dentre elas estão os trabalhos de WALL (1986), FRIEDMAN (1981), FEETHAM (1991), WHALL; FAWCETT (1991), WRIGTH; LEAHEY (1994) e WRIGTH; WATSON; BELL, (1996).

Conforme é referido por FRIEDEMANN (1989), a Enfermagem da família é praticada em três niveis. No primeiro, o foco é o indivíduo e a família é o

\footnotetext{
* Professor Doutor do Departamento de Enfermagem Materno-Infantil e Psiquiátrica da Escola de Enfermagem da USP.

** Professor Titular do Departamento de Enfermagem Materno-Infantil e Psiquiátrica da Escola de Enfermagem da USP.
} 
contexto; no segundo, chamado de nivel interpessoal, a família consiste na unidade maior. O último é o nivel dos sistemas, a família é um sistema com um funcionamento e estrutura própria, desenvolvendo interações com outros sistemas maiores e com seus próprios subsistemas.

\section{A autora argumenta ainda,}

"é aceitável que a enfermeira generalista pratique a enfermagem da família, quando está tratando individuos $e$ inclui os familiares num processo de comunicação. Contudo, tal enfermagem voltada às relações interpessoais, só é praticada pela enfermeira que se aproxima de mais de um membro da familia e focaliza o processo de comunicação para áreas apropriadas às vivências familiares”.

Em um aprofundamento na literatura sobre conceitos de enfermagem de família, WRIGTH; LEAHEY (1990), focalizam a "Enfermagem de Sistemas Familiares". Assim, o cliente passa a ser o sistema familiar, isto é, a família torna-se a unidade do cuidado. O cuidado de enfermagem no contexto da saúde e da doença, com ênfase nas respostas da família aos problemas atuais e potenciais de saúde que a família esteja vivenciando. Os trabalhos das autoras ajudam na compreensão do estudo e atendimento da família como unidade e, não, como a soma da individualidade de cada membro da família.

WRIGTH; LEAHEY (1994) definem intervenção como sendo as respostas da enfermeira às da familia que na seqüência, recebe outra resposta da enfermeira. As autoras também trazem contribuições importantes ti fundamentação teórica da avaliação e intervenção com a família, bem como modelos de avaliação e intervenção familiar, ao qual chamam de "Calgary Family Assessment and Intervention Model (CFAIM)". Estes instrumentos permitem reconhecer o grupo da família para: avaliar, planejar, intervir e reavaliar estão, fundamentalmente, relacionados ao funcionamento da família.

A partir do olhar de "experienciar doença" WRIGHT; WATSON; BELL (1996), ampliam os modelos de Calgary descrevendo a abordagem adotada por elas para a prática com a família. Este é um modelo de crenças na saúde "health belief model". O foco do modelo está na intersecção entre as crenças da pessoa doente, dos membros da familia e as dos profissionais de saúde. As autoras acreditam que, a partir deste modelo, é possivel obter dados sobre as crenças da família, bem como dos profissionais, dando direções de como -ser útil a cada família em particular. Acreditam que, conhecendo como a familia percebe a doença e, oferecendo outros formas, outras lentes, outros olhares possiveis, podemos ajudá-la a viver a experiência de responder à doença ou às relações que demandam da doença.

Outros autores também trazem modelos de avaliação da familia como FRIEDMAN (1992) e HANSON, (1996), no entanto, estes não são suficientes para criar intervenções a partir da experiência da família nas situações de sofrimento que vivem em nossa prática.

Em nosso meio, trabalhos como os de AMARAL (1981), ANGELO (1982) e NEIRA HUERTA (1984) representam o início de um movimento voltado a ampliar os conhecimentos ao atendimento dos familiares. No entanto, conforme indica ANGELO (1997), a falta de referenciais metodológicos na época, não permitia o preenchimento de vazios que diziam respeito a compreender a experiência vivida pelos familiares de crianças hospitalizadas.

Já é certo que saber quem é a família de seu ponto de vista, conhecer sua estrutura e funcionamento, não nos permitiam reconhecer profundamente sua experiência. Era preciso contextualizar a familia e outra perspectiva para enxergá-la.

A partir do exercício teórico apresentado por ANGELO (1997) propondo uma abordagem para o trabalho com família na visão do Interacionismo Simbólico, chegamos a um caminho para trabalhar com a família a partir da experiência dela.

Segundo ANGELO (1997), nesta perspectiva,

"a família é entendida não apenas como unidade biológica e natural, mas como um espaço social, portanto, interacional onde cada evento é vivido a partir de significados construidos simbolicamente."

O Interacionismo Simbólico enquanto perspectiva, segundo CHARON (1989), tem o propósito de compreender a causa da ação humana, causa esta transformada de maneira a significar definição humana, autodireção e escolha nas situações. Neste sentido, reconhece que parte da ação humana é escolha, sendo assim, é livre. O Interacionismo Simbólico considera uma cuidadosa descrição da interação humana como objetivo central das ciências sociais.

Um dos motivos que me levou a optar por esta perspectiva foi seu foco. O interacionismo simbólico, quando adaptado a estudos de família, tem como foco principal o funcionamento interno da mesma.

$\mathrm{Na}$ perspectiva interacionista, ANGELO(1997) traz uma nova definição de família :

"Família é um grupo de individuos em interação simbólica, chegando às situações com os outros significantes ou grupos de referência, com simbolos, perspectivas, self mente e habilidade para assumir papéis". 
Cada individuo tem um passado a resgatar para ajudar a definir a situação e cada um possui uma visão de futuro. Os indivíduos dão significado às situações usando estes instrumentos, às vezes, prestando especial atenção àqueles com quem interagem, outras vezes, usando algo localizado fora da situação como guia. (ANGELO, 1997)

\section{ANGELO (1997) afirma que}

"ao tentarmos compreender as interações no processo familiar em direção à solução de problemas, buscamos identificar o processo mental realizado, pois a tentativa de compreender o outro demanda capacidade para ver o significado das palauras e ações dos outros".

Esta dimensão permite apreendera definição que a familia faz de sua experiência, considerando que esta é a resultante do alinhamento de cada ação individual.

Voltamos então, nossas indagações referentes à experiência da família de crianças internadas em UTI pediátrica: Como os membros da família definem a experiência da criança internada em UTI pediátrica? De que maneira a internação da criança em UTI pediátrica interfere no funcionamento da família e como se processam as interações, após a internação da criança?

Diante destas indagações, desenvolvemos este estudo a partir dos seguintes objetivos: Compreender o funcionamento da dinâmica familiar da criança internada em UTI pediátrica e construir um Modelo Teórico sobre a experiência da familia que vivencia a internação da criança na Unidade de Terapia Intensiva Pediátrica.

A abordagem qualitativa selecionada ao presente estudo foi a Teoria Fundamentada nos Dados proposta por GLASER; STRAUSS (1967). O termo "Teoria Fundamentada nos Dados" refere-se à descoberta de teoria a partir de dados sistematicamente obtidos e analisados pela comparação constante destes, de um ir e vir aos dados, da coleta para a análise e da análise à coleta. (GLASER; STRAUSS, 1967).

\section{O Contexto da Coleta de Dados}

Os dados foram coletados em dois locais. O primeiro deles trata-se de uma Unidade de Terapia Intensiva pediátrica (UTIp) de um hospital escola da cidade de São Paulo. O outro local de coleta, foi um hospital privado da cidade de São Paulo, que atende a pacientes conveniados de várias seguradoras.

\section{A Familias participantes}

Em razão da natureza qualitativa do estudo e a coleta de dados ser dirigida à elaboração de construtos teóricos, conforme descritos anteriormente, utilizamos o que GLASER; STRAUSS (1967) denominam "amostra teórica". Conforme os autores, amostra teórica é o processo de coleta de dados para gerar teoria, onde o pesquisador ao mesmo tempo coleta, codifica e analisa seus dados e decide que dados coletará em seguida e onde encontrá-los, de modo a desenvolver a teoria. O processo de coleta de dados é controlado pela teoria que emerge, seja ela substantiva ou formal.

O número de familiares foi se configurando em razão de análise de seus depoimentos e das observações realizadas. A medida que a análise dos dados prosseguia, as reflexões indicavam que outros dados deveriam ser coletados, para que as categorias fossem sendo melhor desenvolvidas e densificadas. A coleta de dados foi realizada até acontecer a saturação teórica, quando se verificou repetição e ausência de dados novos, e crescente compreensão dos conceitos identificados. Assim, fizeram parte do estudo 14 famílias cujas crianças encontravam-se internadas nas UTIp.

\section{A Obtenção de Dados}

As estratégias adotadas para a coleta de dados foram a observação e a entrevista. A observação faz com que o pesquisador se aproxime da perspectiva dos sujeitos, uma vez que acompanha as experiências e tenta apreender o significado que eles atribuem à realidade e às suas próprias ações. (LUDKE; ANDRÉ, 1986)

A entrevista é uma janela específica, em uma certa hora, em determinado mundo social e, que a pessoa experiencia em determinada situação conforme se referem RUBIN; RUBIN (1995). Afirmam também que, entrevistas qualitativas têm como objetivo entender a experiência da pessoa e assim, uma experiência não é mais verdadeira do que a outra.

O procedimento foi realizado da seguinte forma: conversamos com os membros da família esclarecendo os objetivos da pesquisa bem como, nos certificando de seu interesse em participar do estudo, pedimos aos familiares que assinassem o termo de consentimento caso concordassem.

Começamos cada entrevista pedindo para que eles contassem quem era a família. Conforme descreviam, realizávamos um genograma (mapa das pessoas que compõem a familia) identificando a posição que cada membro ocupa e seus papéis. Nas primeiras entrevistas, a questão norteadora foi: "Como está sendo para vocês e para a familia, estar com um filho internado na UTIp?" 
Deixávamos a família contar sua história, da forma como fizesse mais sentido para ela, porém retomava o foco sempre que era necessário. A medida que as categorias foram se formando, nós acrescentávamos novas perguntas que pudessem esclarecer as idéias trazidas por elas.

Todas as entrevistas foram gravadas e posteriormente transcritas na integra. Elas tiveram duração que variou entre 40 minutos a 1 hora. Foram realizadas um total de 24 entrevistas.

\section{A Análise dos Dados}

Após realizar as duas primeiras entrevistas, iniciamos a codificação aberta examinando cada entrevista, linha por linha Após esta codificação inicial, pelo processo de comparação os códigos foram agrupados um a um por suas similaridades e diferenças conceituais formando as categorias. As categorias receberam nomes mais abstratos que os códigos, de forma que pudessem agrupar conceitos menos abstratos. Algumas mudaram de nomes várias vezes, até que finalmente foram rotuladas com nomes que realmente representavam o significado dos códigos que elas agrupavam.

Conforme codificava e categorizava, faziamos perguntas que pudessem dar seqüência aos dados, e assim, outros elementos eram buscados até densificar as categorias e alcançar a saturação teórica. O método de comparação constante foi adotado durante todo o processo, para auxiliar a identificar e desenvolver as categorias.

Prosseguindo na análise, passamos à etapa seguinte que GLASER (1978) denomina de codificação teórica. Nesta fase as categorias são reorganizadas. Faz-se conexões entre as categorias e suas subcategorias, de forma a realizar agrupamentos, unindo-se as categorias que parecem se referir a um mesmo fenômeno. Na codificação teórica o foco está em especificar as categorias a um fenômeno, a partir dos aspectos que dela se sobressaem.

O mesmo autor apresenta dezoito tipos de codificação teórica que proporcionam ao pesquisador, maior sensibilidade sobre o que explorar e escrever em cada ponto da análise. Para a codificação teórica, utilizei dois tipos: o primeiro é denominada de "seis 'C"' (causa, contexto, contingências, conseqüências, condições e covariantes) e que segundo o autor deve ser o primeiro modelo de codificação geral que um pesquisador social deve ter em mente. O segundo tipo utilizado foi, o de "estratégias". Este tipo permite pensar nas várias maneiras de organizar os mecanismos, as estratégias e arranjos que as pessoas utilizam em suas interações sociais.
Isto foi feito com cada grupo de categoria que formou os fenômenos. Até que chegou a hora de partir para um nivel maior de abstração, ou seja, a descoberta da categoria central. Esta fase é caracterizada pelo desafio de integrar as categorias para formar uma teoria fundamentada nos dados.

Conforme STRAUSS; CORBIN (1990) afirmam, a categoria central "é o fenômeno central, no qual todas as outras categorias estão integradas a seu redor". E aquela que parece ampla e abstrata o bastante para incluir e exprimir todas as demais. Tendo seguido todas as etapas, foi possivel propor o modelo Teórico que explica a experiência vivida pela família com um filho internado na UTI pediátrica.

Para validar o modelo teórico, usamos a estratégia de apresentá-lo a duas famílias. Ambas as famílias identificaram-se com a experiência considerando o modelo representativo do que vivenciaram.

\section{COMPREENDENDO A EXPERIÊNCIA DA FAMÍLIA}

A comparação e análise minuciosa dos dados possibilitaram desvendar os significados da experiência da família com uma criança internada na UTI pediátrica. Neste processo, foi possivel identificar dois fenômenos que compõem a experiência: TENDO UMA RUPTURA FAMILIAR e VIVENDO A
POSSIBILIDADE DE VIR A PERDER O FILHO

A partir da análise dos fenômenos e da maneira como interagem entre si, na experiência da família, foi possivel identificar a categoria central BUSCANDO PRESERVAR A INTEGRIDADE DA UNIDADE FAMILIAR que integra os dois fenômenos.

O início do processo é marcado pela família TENDO UMA RUPTURA FAMILIAR, caracterizado por uma série de perdas como perdendo o poder sobre a criança, não tendo a mesma intimidade com a criança. Existe uma incapacidade da criança de interagir com eles da forma como fazia antes, limitando sua participação na vida familiar. A criança, ainda que temporariamente, não é mais da familia, mas sim, da equipe da UTI.

Outra perda que a família sofre, é também a causa deste processo acerca do significado de ter um filho internado na UTI, é uma ruptura em sua estrutura, caracterizada pela separação, pelo deslocamento entre os membros da família. E a criança na UTI, os pais no hospital, os outros filhos em casa. Com a criança internada na UTI, a família depara-se tendo barreiras que a impossibilitam de permanecer 
com a criança, cuidando e protegendo como sempre o fez. Esta é a situação a que a família é submetida, com a internação da criança na UTI.

No contexto deste processo, a familia define UTI como sendo um lugar para morrer. esta definição coloca a família próxima à questão da morte, do sentido da vida, do sofrimento insuportável e, conseqüentemente, frente a uma possivel ruptura definitiva da unidade familiar. Assim, a internação da criança, está fora do tempo cronológico da família. É uma experiência prematura, jamais esperada para uma criança, deixando a família com medo do filho morrer.

Diante do ambiente da UTI, a família é confrontada com incertezas. A possibilidade da morte da criança causa um impacto enorme nas relações familiares. Entretanto, a espera vivida pela família durante este processo não é passiva. A família não fica simplesmente aguardando o depois; mas, busca caminhos, elabora estratégias, faz arranjos, enquanto aguarda VIVENDO A POSSIBILIDADE DE VIR A PERDER O FILHO.

VIVENDO A POSSIBILIDADE DE VIR A PERDER O FILHO é então, a conseqüência do processo. Desde o momento em que a família se conscientiza da possibilidade de vir a sofrer uma ruptura definitiva, inicia-se uma série de reflexões e ações direcionadas no sentido de preservar a meta principal - BUSCANDO PRESERVAR A INTEGRIDADE DA UNIDADE FAMILIAR.

Preocupada com a possibilidade da separação definitiva pela ameaça de morte da criança, imediatamente a família elabora uma série de estratégias, no sentido de ser capaz de preservar a vida da criança e manter sua unidade.

Acreditando que pode ajudar a criança diz respeito às reflexões da família quanto às suas responsabilidades sobretudo como pais, na possibilidade de proteger a criança, de tentar preservar a integridade da unidade familiar, bem como da esperança de poder evitar a morte da criança. Este componente influencia fortemente as decisões da família na elaboração de estratégias, surgindo novas regras de relacionamento familiar que se estabelecem em face da ameaça da perda do filho.

A perda do poder sobre a criança leva a uma imobilização inicial; no entanto, tentando evitar uma cisão definitiva a família elabora um reposicionamento dos papéis direcionando toda energia à criança doente. Com esta tática, a família como um todo fica a postos, pronta para fazer qualquer coisa que possa ajudar à criança. Vivendo em função da criança doente, a familia busca ter algum conhecimento da doença e assim, fica com a sensação de restabelecimento de algum controle da situação, tentando evitar uma cisão definitiva.
A familia assume que a prioridade agora é a vida da criança. Sofre com os rearranjos nas relações familiares, ficando longe de casa e dos outros filhos, mas define que estas atitudes agora não são essenciais para preservar a familia. Entende que sua responsabilidade, agora, é proteger sua unidade e que o resto poderá ser retomado depois. Neste sentido, para que seja possivel atingir o objetivo, utiliza mecanismos redirecionando todos os relacionamentos, priorizando assegurar os laços da família, principalmente, não deixando romper o elo com a criança doente, BUSCANDO PRESERVAR A INTEGRIDADE DA UNIDADE FAMILIAR.

É parte do processo, ainda, o sofrimento presente frente às incertezas que a experiência impõe. No entanto, o conjunto da experiência evidencia reações da família onde se observam estratégias que são elaboradas, dirigidas não só à preservação da estrutura familiar, como também à manutenção de relacionamentos que permitam à família manter-se unida. Quando a família se une, busca forças e esperança para superar as incertezas e é um esforço conjunto, de todo o grupo familiar.

Neste processo, BUSCANDO PRESERVAR A INTEGRIDADE DA UNIDADE FAMILIAR é também o que impulsiona a família a seguir em frente. A manobra agora é evitar conflitos e procurar oferecer apoio um para o outro. A família utiliza a estratégia de se apoiar para não desanimar, pelo menos não todos juntos, evitando um desmoronamento.

Diante da falta de alternativa para viver ou não esta experiência, ficar unida é uma posição que também vai assegurando à família recarregar suas forças a fim de continuar conseguindo arranjar meios com vistas a atingir seu objetivo - Preservar a unidade familiar. Entretanto, nem sempre a família consegue se sustentar somente com suas próprias forças; às vezes, ela desanima, mas percebe-se tendo ajuda para poder suportar.

Nestas fases, passa a ser essencial a ajuda que a família recebe de outros parentes, amigos e outras famílias, no sentido de ir transformando a definição UTI como sendo um lugar para morrer, dando esperança e, assim, deixando os familiares fortalecidos para prosseguirem na caminhada.

As familias que estão lidando com experiências semelhantes, desenvolvem relacionamentos significativos nas salas de espera da UTI. Os familiares escutam as mesmas histórias contadas por outras famílias; por vezes deparando-se com outros padrões históricos, culturais, éticos e religiosos que os ajudam a refletir o que estão passando, deixando-os com mais esperança e sentindo-se mais fortes. 
Com este mecanismo, a família elabora seu próprio suporte no ambiente da UTI e, assim, acaba tornando-se parte importante no conjunto umas das outras, servindo de suporte para atingir sua meta de preservar a unidade familiar.

As perspectivas que desenvolve em relação à doença da criança e, conseqüentemente, também em relação à sua unidade surgem também destas interações que se estabelecem na vivência do hospital. Encarar perdas vividas por outras famílias, vendo outras crianças morrendo, pode deixar real para a familia que, as doenças fatais não acontecem só no final da vida, só com adultos e não com crianças, colocando os familiares diante da possibilidade da morte do próprio filho.

À medida que os recursos financeiros e emocionais esgotam-se, os familiares sentem-se sofrendo uma pressão social e vão retomando suas atividades. A familia, geralmente o pai, volta a trabalhar, pois precisa do dinheiro para continuar BUSCANDO PRESERVAR A INTEGRIDADE DA UNIDADE FAMILIAR.

Estando vivendo incertezas por algum tempo, chega o momento em que a experiência se define. $\mathrm{O}$ processo finaliza de duas formas, com a família tendo o filho de volta, podendo interagir novamente com a criança, conseguindo enxergar um futuro no qual pode incluir a criança; pode voltar a tomar decisões sobre a criança reassumindo o poder sobre o filho. assim, a família atinge seu objetivo tendo a unidade familiar preservada.

$\mathrm{Na}$ outra forma, a família reconhece que está perdendo a batalha, depara-se com sua inabilidade em proteger a criança da morte tendo uma cisão definitiva. Reconhece que todos os esforços investidos pela equipe médica e que os meios utilizados por ela na busca da preservação de sua unidade, não foram suficientes para manter a criança viva. Ainda assim, pensa em estratégias futuras para preservar a unidade familiar, evitando mais perdas.

A incerteza se encerra com a esperança, caracterizada pela morte da criança e definindo a ruptura definitiva, não sendo possivel preservar a mesma unidade familiar.

O modelo teórico descrito e representado pelo diagrama 1 tem, portanto, como categoria central BUSCANDO PRESERVAR A INTEGRIDADE DA UNIDADE FAMILIAR, capaz de integrar os componentes relacionados às causas e às conseqüências vivenciadas pela família com o filho internado na UTI.

Diagrama 10 Processo "Buscando Preservar a integridade da unidade familiar"

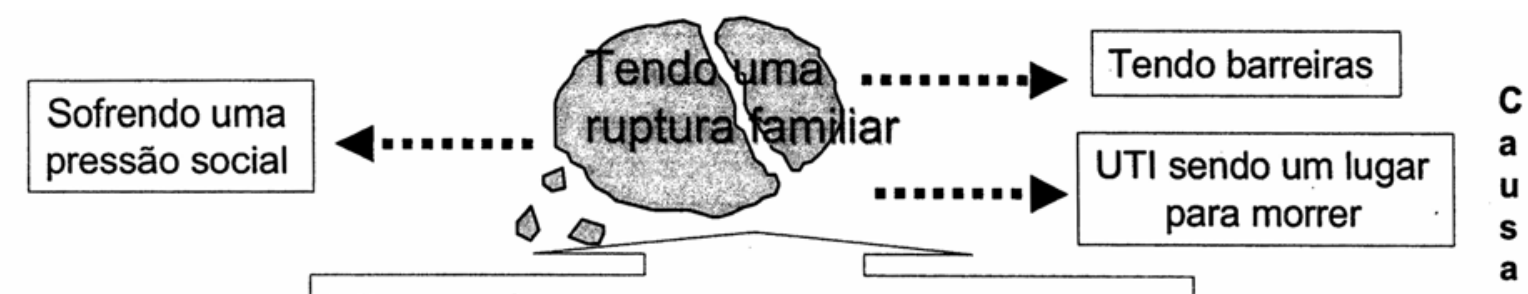

Vivendo esperas apreensivas

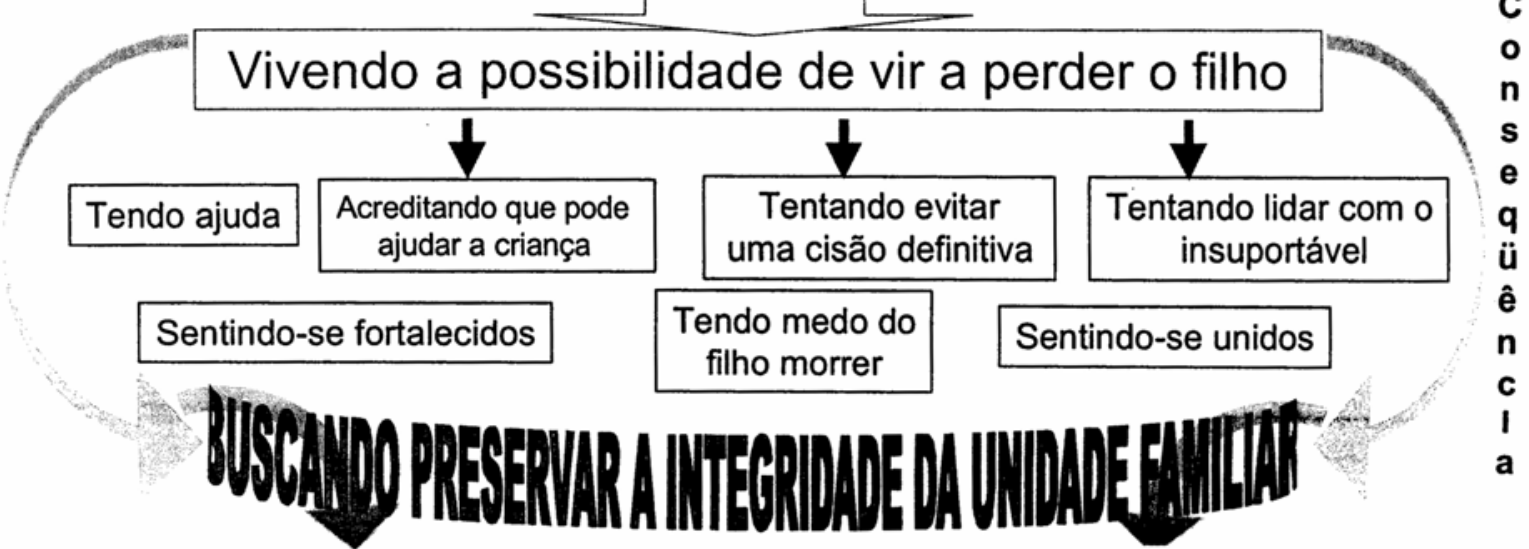

Tendo uma cisão
definitiva
Tendo o filho de volta

Reassumindo o poder 


\section{REFLETINDO SOBRE O PROCESSO}

O impacto da internação da criança em UTI pediátrica sobre a família tem sido documentado na literatura, tanto em nivel nacional como internacional, enfatizando sobretudo sentimentos e necessidades da família face à doença da criança. A familia aparece como contexto da situação e não como foco de pesquisa. Poucos estudos abordam estas necessidades a partir da experiência da família.

$\mathrm{Na}$ perspectiva do Interacionismo Simbólico, a familia é uma unidade de pessoas em interação. Nesta perspectiva de olhar a experiência da familia, sabe-se que o significado da experiência está presente para todos os membros da família e, portanto, deve ser visto numa dimensão maior, integral, de um conjunto de pessoas interagindo, uma "pequena sociedade".

Os trabalhos que mais se aproximaram da experiência da família tendo-a como foco do estudo, descrevem a ocorrência de alterações na dinâmica familiar em situações de doenças crônicas. A experiência da família que vivencia a internação da criança na UTI, tendo como foco a dinâmica familiar não aparece documentada nas publicações de enfermagem. Vale ressaltar que a permanência da família na UTI também é uma situação recente em nossa realidade, o que não permitiu ainda tanto investimento em pesquisas com esta temática e, conseqüentemente, produção de conhecimento que pudesse ser divulgado.

Sendo assim, a metodologia que utilizamos visando compreender à família, permitiu a exploração de aspectos da experiência da família, pouco contemplados nos estudos existentes.

A família, como parte essencial para o cuidado de enfermagem, é algo inquestionável. As enfermeiras freqüentemente estão envolvidas com as famílias durante as fases de sofrimento e assim têm uma oportunidade única de fazer diferença na experiência de seu sofrimento. No entanto, são muitos os obstáculos no caminho daqueles que se dispõem a ajudá-la.

Concordamos com ANGELO (1997), quando diz que

"as ações de apoio oferecidas são tímidas $e$ pouco efetivas, porque não atingem a experiência da família e sequer a do enfermeiro, que se deixa guiar pelo perigoso bom- senso, supondo saber como as familias devem se sentir e agir em determinadas circunstâncias".
È preciso que se desenvolvam e apliquem-se modelos conceituais mais amplos para uma prática avançada com famílias. Não devemos pensar que esta seja uma situação apenas em nível nacional. RENNICK (1995) ressalta que, para ser uma realidade concreta, esta temática deverá ser mais explorada.

Ainda assim, nosso entendimento sobre a experiência da família está começando. É necessário prosseguirem as investigações que nos mostrem mais e melhor como a familia vivencia diferentes experiências, trazendo novos modelos teóricos que permitam à enfermeira apreender o que está se passando com a família, dando mais sentido às proposições e à sua intervenção.

$\mathrm{O}$ processo permitiu-nos viver e acreditar mais intensamente no que dizem ROBINSON; WRIGTH (1995) sobre as respostas do enfermeiro no processo de trabalho de enfermagem com família. As autoras referem que as enfermeiras conduzem satisfatoriamente a avaliação da família, mas que só esta não é suficiente para cumprir nosso dever de aliviar o sofrimento fisico e emocional do paciente e da familia. É hora de sistematicamente nos compadecermos das famílias e intervir com compaixão para ajudá-las a exteriorizar sua dor. Diálogos, novos modelos teóricos, pesquisas são essenciais à efetivação do processo. No entanto, é somente com a coragem de traduzir conhecimentos, transformando-os em modelos teóricos e estratégias de intervenções com a família que iremos de fato ajudá-las a aliviar o sofrimento.

Assim, o modelo teórico que tem como categoria central BUSCANDO PRESERVAR A INTEGRIDADE DA UNIDADE FAMILIAR representa o processo que explica o significado de ter um filho internado em UTI pediátrica para a família. Sendo um processo, conforme preconiza a Teoria Fundamentada nos Dados, não deve ser dado como fechado, podendo ser ampliado ou modificado a partir do momento que outros dados forem acrescentados à compreensão da realidade.

Fica aqui um desafio, aos profissionais, no sentido de usar, refletir, ampliar ou modificar este modelo. 


\section{REFERÊNCIAS BIBLIOGRÁFICAS}

AMARAL, ML. Sentimentos e solicitações apresentados pelas mães no momento de internação de seus filhos. São Paulo, 1981. 82p. Dissertação (Mestrado) - Escola de Enfermagem, Universidade de São Paulo.

ANGELO, M. Com a familia em tempos dificeis: uma perspectiva de enfermagem. São Paulo, 1997. 117 p. Tese (Livre Docência) - Escola de Enfermagem, Universidade de São Paulo.

ANGELO, M. Experiência das mães na visita ao filho hospitalizado. São Paulo, 1982. 70p. Dissertação (Mestrado) Escola de Enfermagem, Universidade de São Paulo.

CHARON, JM. Symbolic interacionism: an introduction an interpretation, an integration. 3.ed. Englewood Cliffs, PrenticeHall, 1989.

CORBIN, JM; STRAUSS, AL. Collaboration: couples working together to manage chronic illness. Image $J$, v.16, n.4, p.109$15,1984$.

FEETHAM, SL. Conceptual and methodological issues in research of families. In: WHALL, AL; FAWCETT, J. Family theory development in nursing: state of the science and art Philadelphia, F.A.Davis, 1991. p.55-68.

FRIEDEMANN, ML. The concept of family nursing. $J$ Adv Nurs, v.14, n.3, p.211-6, 1989.

FRIEDMAN, MM. Family nursing: theory and practice. 3.ed. Norwalk, Conn., Appleton Lange, 1992.

FRIEDMAN, MM. Family nursing: theory and practice Norwalk, Conn., Appleton Lange, 1981.

FRIEDMAN, MM. Family nursing: theory and assessment. 2.ed. Norwalk, Applenton-Century-Crofts, 1986

GILLIS, CL et al. Toward a science of family nursing. Reading. Mass, Addison-Wesley, 1989.

GLASER, BG; STRAUSS, AL. The discovery of grouded theory. New York, Aldine, 1967.

GLASER, CL. Theoritical sensitivity. Mill Valley, The Sociology Press, 1978.

HANSON, SMH. Family assessment and intervention In: HANSON, SMH; BOYD, ST. Family health care nursing: theory, practice, and research. Philadelphia, F. A. Davis, 1996. Cap.7, p.147-72:

LUDKE, M; ANDRÉ, MEDA. Pesquisa em educação: abordagens qualitativas. São Paulo, EPV, 1986.

MARTIN, K. When a baby dies of sides: the parent's grief and search for reason. Edmonton, Alberta, International Institute for Qualitative Methodology, 1998.

MONTIGNY, F; BEAUDET, L. Lorsque la vie éclate: 1' impact de la mort d'un enfant sur la famille. Québec, ERPI, 1997. Cap. 13, p. 381-412: Strategies d'intervention auprès des families endeuillées.
NEIRA HUERTA, E del PN. A experiência de acompanhar um filho hospitalizado: sentimentos, necessidades e expectativas manifestadas por mães acompanhantes. São Paulo, 1984. 218p. Dissertação (Mestrado) - Escola de Enfermagem, Universidade de São Paulo.

RENNICK, JE. The changing profile of acute childhood illness: a need for the development of family nursing knowledge. $J \mathbf{A d v}$ Nurs, v.22, n.2, p.258-66, 1995.

ROBINSON, CA; WRIGHT, LM. Family nursing interventions: what families say makes a difference. J Fam Nurs, v.1, n.3, p.327-45, 1995.

RUBIN, HJ; RUBIN, IS. Qualitative interviewing: the art of hearing data. Thousand Oaks, Sage, 1995.

STRAUSS, A; CORBIN, J. Basics of qualitative research: grounded theory procedures and techniques. California, Sage, 1990.

WALL, A. The family as the unit of care: a historical review. Public Health Nurs, v.3, n.4, p.240-9, 1986.

WHALL, AL; FAWCETT, J. The family development in nursing: state of the science and art. Philadelphia, F.A.Davis, 1991. Cap.1,p.7-29: The family as a focal phenomenon in nursing.

WRIGHT, LM; LEAHEY, M. Nurses and families: a guide to family assessment and intervention. Philadelphia, F.A.Davis, 1994. Cap.', p.1-21: Concepts of family intervening.

WRIGHT, LM; LEAHEY, M. Trends in nursing of families. $J$ Adv Nurs, v.15, n.2, p.148-54, 1990.

WRIGHT, LM; WATSON, WL; BELL, JM. Beliefs: the heart of healing in families and illnes. New York, Basic Books, 1996.
Artigo recebido em 15/09/00

Artigo aprovado em 21109101 